\title{
Acompanhamento e ações de apoio oferecidas aos professores iniciantes no contexto escolar
}

\author{
Accompanying and supporting actions offered to teachers initiating in \\ the school context
}

\section{Acompañamiento y acciones de apoyo ofrecidas a los profesores iniciantes en el contexto escolar}

\author{
Dirlene Glasenapp' \\ Associação Catarinense de Ensino - Faculdade Guilherme Guimbala, Professora do Curso de \\ Pedagogia \\ https://orcid.org/0000-0002-3450-6646

\section{Marcia Souza Hobold ${ }^{2}$} \\ Universidade Federal de Santa Catarina, Programa de Pós-graduação em Educação, \\ Departamento de Metodologia de Ensino do Centro de Ciências da Educação, Professora \\ https://orcid.org/0000-0002-4179-608x
}

Resumo: Este estudo visou analisar de que modo os professores iniciantes são acompanhados no cotidiano de sua prática pedagógica e quais ações de apoio lhes são oferecidas no contexto escolar por parte dos diretores e supervisores escolares. Trata-se de uma pesquisa que teve como objetivo conhecer o processo de acompanhamento e as ações de apoio oferecidas aos professores iniciantes na Rede Municipal de Ensino de um município catarinense. Caracteriza-se como uma investigação de cunho qualitativo, em que se utilizou a entrevista semiestruturada como instrumento para a coleta de dados e a análise de conteúdo para sua interpretação. Os participantes são diretores, supervisores escolares e professores experientes, ou seja, profissionais que recebem os docentes iniciantes nas escolas de Ensino Fundamental. Os principais autores que sustentam os aportes teóricos são: García (1999, 2009), Giovanni e Guarnieri (2014), Imbernón (2011), Libâneo (2008), Nono (2011) e Placco, Souza e Almeida (2012). Os resultados apontam que são oferecidas aos professores iniciantes ações pontuais, de acordo com as demandas vivenciadas no contexto escolar. Os dados revelam, ainda, que o acompanhamento desses professores é realizado preponderantemente pelos supervisores escolares, sendo que a direção se envolve mais nos aspectos administrativos concernentes a esse profissional. Porém, a sobrecarga de trabalho dos supervisores escolares não tem

Mestra em Educação pela Universidade da Região de Joinville; Especialista em Psicopedagogia, com ênfase em Alfabetização, pela Universidade da Região de Joinville.

2 Pós-Doutora (CNPq PDJ) pela Pontifícia Universidade Católica de São Paulo; Doutora em Educação pela Pontificia Universidade Católica de São Paulo. 
favorecido a realização de um acompanhamento sistemático desses docentes, o que pode fragilizar o processo de desenvolvimento profissional do professor iniciante.

Palavras-chave: Professores iniciantes. Ações de apoio e acompanhamento. Diretores e supervisores escolares.

Abstract: This estudy aimed to analyze how the beginning teachers are accompanied in the daily of their pedagogical practice and what support actions are offered to them in the school context, by the school principals and supervisors. It is a research that had as objective to know the follow-up process and the support actions offered to beginners teachers in the Municipal Teaching Network of a municipality in Santa Catarina. It is characterized as a qualitative research, in which the semi-structured interview was used as an instrument for data collection and content analysis for its interpretation. The participants are principals, school supervisors and experienced teachers, that is, professionals who receive the beginning teachers in elementary schools. The main authors who support the theoretical contributions are: García (1999, 2009), Giovanni and Guarnieri (2014), Imbernón (2011), Libâneo (2008), Nono (2011) and Placco, Souza and Almeida (2012). The results point out that beginning teachers are offered punctual actions, according to the demands experienced in the school context. The data also reveal that the monitoring of these teachers is carried out predominantly by school supervisors, and the management is more involved in the administrative aspects concerning this professional. However, the work overload of school supervisors has not favored the systematic monitoring of these teachers, which may weaken the process of professional development of the beginning teacher.

Keywords: Beginning teachers. Support and follow-up actions. School principals and supervisors.

Resumen: Este estudio buscou analizar de qué modo los profesores principiantes son acompañados en el cotidiano de su práctica pedagógica y qué acciones de apoyo les son ofrecidas en el contexto escolar, por parte de los directores y supervisores escolares. Se trata de una investigación que tuvo como objetivo conocer el proceso de acompañamiento y las acciones de apoyo ofrecidas a los profesores principiantes en la Red Municipal de Enseñanza de un municipio catarinense. Se caracteriza como una investigación de cuño cualitativo, en la que se utilizó la entrevista semiestructurada como instrumento para la recolección de datos y el análisis de contenido para su interpretación. Los participantes son directores, supervisores escolares y profesores experimentados, es decir, profesionales que reciben los docentes principiantes en las escuelas de Enseñanza Fundamental. Los principales autores que sostienen los aportes teóricos son: García (1999, 2009), Giovanni y Guarnieri (2014), Imbernón (2011), Libneo (2008), Nono (2011) y Placco, Souza y Almeida (2012). Los resultados apuntan que se ofrecen a los profesores principiantes acciones puntuales, de acuerdo con las demandas vivenciadas en el contexto escolar. Los datos revelan que el acompañamiento de estos profesores es realizado preponderantemente por los supervisores 
escolares, mientras que la dirección se involucra más en los aspectos administrativos concernientes a ese profesional. Sin embargo, la sobrecarga de trabajo de los supervisores escolares no ha favorecido la realización de un seguimiento sistemático de estos docentes, lo que puede debilitar el proceso de desarrollo profesional del profesor principiante. Palabras clave: Profesores principiantes. Acciones de apoyo y seguimiento. Directores y supervisores escolares.

Recebido em 17 de dezembro de 2018
Aceito em 22 de julho de 2019
Publicado em 23 de agosto de 2019

\section{INTRODUÇÃO}

0 início da docência é compreendido como o período de passagem de estudante a professor. Constitui-se como uma fase marcada por desafios, na qual o profissional recém-formado passa a ter contato com seu campo de atuação. Nesse contexto, surgem dúvidas e dificuldades que precisam ser superadas. A escola emerge como um espaço de formação em que a troca de saberes com os pares e o acompanhamento por parte da equipe pedagógica podem se tornar elementos contributivos para o desenvolvimento profissional do docente.

Diante disso, considera-se importante a oferta de ações de apoio aos professores iniciantes no contexto escolar por parte da equipe gestora (diretores e supervisores escolares), bem como a efetivação de um acompanhamento sistemático desses profissionais, a fim de orientá-los na realização de suas práticas docentes. Partindo dessa premissa, esta pesquisa buscou identificar junto aos profissionais que recebem os professores iniciantes nas escolas, ou seja, diretores, supervisores escolares e professores experientes, quais ações de apoio e acompanhamento são oferecidas a eles.

Tendo como base o contexto apontado e os dados obtidos com os participantes da pesquisa, este artigo traz uma breve discussão conceitual sobre professores iniciantes e a escola como espaço de aprendizagem da docência, destacando as atribuições do diretor e do supervisor escolar nesse processo. Também se apresenta o percurso metodológico da investigação desenvolvida e realiza-se uma análise sobre o acompanhamento e as ações de apoio oferecidas aos professores iniciantes no contexto escolar, tomando-se por base as falas desses profissionais. 


\section{PROFESSORES INICIANTES E A ESCOLA COMO ESPAÇO DE APRENDIZAGEM DA DOCÊNCIA}

0 período inicial da docência é compreendido como uma das etapas do processo de desenvolvimento profissional, que abrange também o período de pré-formação, a formação inicial e a formação permanente (GARCÍA, 1999). Para o autor,

\footnotetext{
[...] a iniciação ao ensino é o período de tempo que abarca os primeiros anos, nos quais os professores fazem a transição de estudantes para professores. É um período de tensões e aprendizagens intensivas em contextos geralmente desconhecidos, e durante o qual os professores principiantes devem adquirir conhecimento profissional além de conseguirem manter um certo equilibrio pessoal. (GARCíA, 1999, p. 113).
}

De acordo com Huberman (2007), a carreira docente é constituída por diversas fases, cada qual com características próprias, mas que podem ser vivenciadas de modos distintos, apresentando-se linearmente para alguns e de forma descontínua para outros. Segundo o autor, o período de inserção na docência compreende os três primeiros anos de atuação profissional. É a entrada na carreira, a fase do tateamento, da exploração, que consiste em investigar os contornos da profissão a partir do contato inicial com as situações de sala de aula, sendo marcada pelos estágios de sobrevivência e descoberta. Ao referir-se ao aspecto da sobrevivência, Huberman (2007) descreve-o como o "choque do real", período este em que o professor se depara com a complexidade do campo profissional, caracterizada por diversos fatores, entre os quais a distância entre o ideal e o real vivenciado em sala de aula, as dificuldades enfrentadas com alunos que criam problemas, a fragmentação do trabalho, as dificuldades com material didático inapropriado, a dificuldade em fazer frente à relação pedagógica e à transmissão de conhecimento, etc. 0 aspecto da descoberta é descrito pelo autor como "[...] o entusiasmo inicial, a experimentação, a exaltação por estar, finalmente, em situação de responsabilidade (ter a sua sala de aula, os seus alunos, o seu programa), por se sentir colega num determinado corpo profissional." (HUBERMAN, 2007, p. 39). Para ele, os dois aspectos se dão em paralelo, e são as descobertas que permitem ao professor sobreviver a essa fase inicial da docência.

García (1999) afirma que é durante o processo de iniciação que o professor se socializa no sistema e aprende a conviver com os estudantes, os colegas e os supervisores, buscando alcançar certo nível de segurança para lidar com as situações do dia a dia. 0 autor salienta, ainda, que é possível que os professores experimentem essas características do começo da docência quando mudam para outro nível de ensino, para outra escola ou para outra região, independentemente do tempo de experiência que já possuam na profissão. Desse modo, compreende-se que as particularidades do período inicial da docência podem ser 
revividas quando um professor adentra em um novo contexto educacional, considerando-se que as diferentes instituições educacionais (públicas e privadas) apresentam características próprias quanto à sua estrutura organizacional e, consequentemente, pedagógica.

Giovanni e Guarnieri (2014) enfatizam que os estudos sobre socialização profissional evidenciam as condições em que se dá esse processo. Segundo as autoras,

\begin{abstract}
0s iniciantes e re-iniciantes [sic] chegam aos locais de trabalho tendo muito que aprender: entorno da escola, regras, normas, horários, com quem obter informações, quais turmas assumir, quem são os alunos e suas diferenças, quais condutas adotar [...] enquanto na sala de aula enfrentam a dificil tarefa de ensinar. (GIOVANNI; GUARNIERI, 2014, p. 37).
\end{abstract}

Mesmo sendo relevantes para o exercício da profissão, vários desses aspectos citados anteriormente pelas autoras não integram as matrizes curriculares dos cursos de formação inicial, pois são característicos do contexto escolar, e o período de estágio supervisionado realizado durante a graduação não é suficiente para permitir a aquisição dos conhecimentos necessários para exercer a docência. Desse modo, essa aprendizagem se dará na fase de inserção profissional.

García (2009) defende a premissa de que existem conhecimentos que serão adquiridos apenas mediante a prática docente. 0 autor afirma que

\begin{abstract}
Independentemente da qualidade do programa de formação inicial que tenham cursado, há algumas coisas que só se aprendem na prática e isso repercute em que esse primeiro ano seja um ano de sobrevivência, descoberta, adaptação, aprendizagem e transição. As principais tarefas com que se deparam os professores principiantes são: adquirir conhecimentos sobre os estudantes, o currículo e o contexto escolar; planejar adequadamente $\circ$ currículo e o ensino; começar a desenvolver um repertório docente que thes permita sobreviver como professor; criar uma comunidade de aprendizagem na sala de aula; e continuar desenvolvendo uma identidade profissional. E o problema é que, em geral, devem fazer isso sobrecarregados pelas mesmas responsabilidades dos professores mais experientes. (GARCíA, 2009, p. 128).
\end{abstract}

Considerando-se os conhecimentos a serem adquiridos pelos professores iniciantes mencionados por Giovanni e Guarnieri (2014) e García (2009), é possível perceber que grande parte destes estão relacionados às particularidades de cada escola, o que corrobora a ideia de que as experiências do início da docência podem ser revividas quando um professor já experiente passa a atuar em um novo contexto de trabalho. Nesse caso, as dificuldades didático-pedagógicas podem ser menos acentuadas, porém questões relativas às peculiaridades do local e do grupo de trabalho podem, sim, configurar-se como dificuldades no período de reinício desse professor. 
Entende-se, portanto, que os professores iniciantes, seja na profissão, seja em um novo contexto de atuação, têm necessidade de receber apoio da equipe gestora escolar e também de seus pares, como forma de minimizar as dificuldades que caracterizam esse período da carreira e de contribuir para a aprendizagem da profissão. Considerando-se que diretores e supervisores escolares integram a equipe gestora das escolas, acredita-se que esses profissionais desempenham um papel importante na formação profissional do docente. Em vista disso, faz-se necessário compreender quais funções são atribuídas a cada um desses profissionais no contexto escolar.

De acordo com Souza (2010), o trabalho do diretor se dá em duas perspectivas, a político-administrativa e a político-pedagógica. No que se refere à dimensão políticoadministrativa, cabe-lhe gerir as questões burocráticas, os recursos, o espaço físico e o pessoal, bem como implementar programas e ações oriundos das políticas educacionais, entre outras atribuições. Quanto à dimensão político-pedagógica, compete à direção escolar a mediação, a promoção e o desenvolvimento do planejamento pedagógico, a definição de prioridades e estratégias metodológicas que se ajustem ao contexto educacional, as avaliações institucionais e do processo de ensino-aprendizagem, a melhoria dos índices/ resultados escolares e o atendimento das demandas de formação inicial e continuada dos docentes e não docentes, entre outras funções.

No tocante ao supervisor escolar, Placco, Souza e Almeida (2012), utilizando a denominação mais específica de coordenador pedagógico, afirmam que as atribuições conferidas a esses profissionais pelas legislações estaduais e/ou municipais são inúmeras, perpassando pela liderança do projeto político-pedagógico e por funções administrativas de assessoramento à direção. Contudo, as autoras enfatizam as atividades relacionadas ao funcionamento pedagógico da escola e ao apoio aos professores como as principais funções do supervisor escolar/coordenador pedagógico. Entre essas atividades, pode-se destacar: a supervisão e a organização das ações pedagógicas cotidianas, o andamento do planejamento de aulas (conteúdos ensinados), a organização de avaliações e do material necessário para as aulas e reuniões pedagógicas e também a formação continuada dos professores.

É evidente, portanto, que tanto o diretor quanto o supervisor escolar têm como atribuição acompanhar a prática docente e também promover espaços de formação continuada no âmbito do contexto escolar, a fim de contribuir para a aprendizagem da docência e para o desenvolvimento profissional dos professores, iniciantes ou não.

A ideia da escola como espaço de formação e aprendizagem da docência é amplamente discutida na literatura especializada. Nono (2011, p. 36-37) pontua que 
[...] os professores precisam fazer parte de uma comunidade de aprendizagem - trabalhando com os pares, recebendo apoio e assessoria de um diretor que compreenda as necessidades colocadas pelas políticas públicas em relação ao papel do professor e às necessidades de mudanças de práticas pedagógicas, discutindo suas práticas escolares com outros profissionais que possam oferecer sugestões e comentários - que constitua fonte de apoio e ideias.

Imbernón (2011) salienta que a formação centrada na escola desenvolve um paradigma colaborativo entre os profissionais da educação, que, por meio da reflexão e da pesquisa-ação, buscam elaborar suas próprias soluções para os problemas práticos com os quais se deparam no cotidiano escolar. 0 autor salienta, ainda, que "[...] a formação é tanto mais efetiva quanto mais se aproxima do contexto organizacional do trabalho (formação na escola)." (IMBERNÓN, 2011, p. 81).

Libâneo (2008, p. 230) assevera que

A formação em serviço ganha hoje tamanha relevância que constitui parte das condições de trabalho profissional. Os sistemas de ensino e as escolas precisam assegurar condições institucionais, técnicas e materiais para o desenvolvimento profissional permanente do professor. Especialmente, é imprescindivel assegurar aos professores horas remuneradas para realização de reuniões semanais, seminários de estudo, e reflexões coletivas, onde possam compartilhar e refletir sobre a prática com colegas, apresentar seu trabalho publicamente (contar como trabalham, o que funciona, as dificuldades etc.) [...]

Assim, cabe à escola, na figura dos diretores e supervisores escolares, delinear ações de apoio e acompanhamento ao professor iniciante e promover situações específicas para a formação continuada em serviço, visando colaborar para a aprendizagem da docência e para o processo de desenvolvimento profissional dos docentes.

\section{PERCURSO METODOLÓĠICO}

Esta pesquisa está pautada na abordagem qualitativa, e a coleta de dados se deu por meio de entrevistas semiestruturadas, com o objetivo de identificar ações de apoio e acompanhamento que sejam oferecidas aos professores iniciantes no contexto escolar. Para alcançar o objetivo proposto, foram entrevistados profissionais que trabalham diretamente com os docentes iniciantes no contexto escolar, sendo eles cinco diretores, cinco supervisores escolares (responsáveis pela parte pedagógica das escolas) e cinco 
professores experientes (com tempo de atuação na docência variando entre 12 e 30 anos). Destaca-se que na Rede Municipal de Ensino pesquisada utiliza-se a denominação de supervisor escolar.

0 lócus da pesquisa foi composto por cinco escolas da Rede Municipal de Ensino de uma cidade de Santa Catarina, selecionadas a partir do levantamento de 13 escolas que integraram uma pesquisa anterior, pertencente a um programa stricto sensu em educação e realizada com professores iniciantes. Foi contemplada pelo menos uma escola de cada região (Norte, Sul, Leste e Oeste) do município, com exceção de uma das regiões, na qual foram selecionadas duas escolas, a fim de totalizar cinco unidades. Destaca-se que todas as escolas estão localizadas em áreas urbanas. Identificadas as cinco unidades escolares, fez-se o contato inicial com os diretores, via telefone, a fim de explicar os objetivos da pesquisa e convidar os profissionais a participar. Dado o aceite, as datas para a realização das entrevistas foram agendadas conforme a disponibilidade dos participantes.

As entrevistas foram realizadas após a aprovação do projeto de pesquisa pelo Parecer n. 741.310 do Comitê de Ética em Pesquisas com Seres Humanos, sendo gravadas mediante autorização prévia dos participantes. Finalizado esse processo, as entrevistas foram transcritas, e os dados, categorizados por recorrência, contradição e complementaridade, a partir de indicadores, utilizando-se como técnica a análise de conteúdo proposta por Franco (2012), em que se tem a mensagem como ponto de partida. Para a autora, a análise de conteúdo compreende a linguagem como construção real e dinâmica de toda a sociedade, portanto as mensagens devem ser interpretadas considerando-se o contexto socio-histórico do qual fazem parte seus produtores.

Os dados obtidos com os diretores, supervisores escolares e professores experientes permitiram a percepção de que cada profissional, na sua função, desempenha ações distintas para acompanhar e apoiar o docente iniciante dentro do contexto escolar. As ações identificadas nos relatos dos entrevistados são apresentadas a seguir. Convém pontuar que alguns dados vinculados a duas pesquisas anteriores, realizadas por Gabardo (2012) e Giordan (2014) com professores iniciantes nessa mesma Rede de Ensino, são aqui mencionados a fim de dialogar com os resultados obtidos nesta investigação.

\section{ACOMPANHAMENTO E AÇÕES DE APOIO OFERECIDAS AOS PROFESSORES INICIANTES NO CONTEXTO ESCOLAR}

A pesquisa realizada permitiu identificar as ações de apoio que são oferecidas aos professores iniciantes pelos diretores e supervisores escolares. Algumas dessas ações 
são oferecidas assim que os docentes chegam às escolas, outras thes são oferecidas de acordo com as demandas que surgem no cotidiano da prática pedagógica. Entre as ações identificadas, duas estão diretamente relacionadas aos professores iniciantes, como a recepção inicial e o repasse de informações sobre o funcionamento da escola; outras ações, como o auxílio quanto ao domínio de turma, a organização da hora-atividade e a formação em serviço são oferecidas à totalidade dos professores dentro do contexto escolar.

No tocante à recepção do professor iniciante, pode-se inferir, com base nos relatos, que os professores são recebidos inicialmente pela direção, que os apresenta para - grupo de profissionais e thes mostra o espaço físico da unidade escolar. Os diretores também repassam informações ligadas à parte administrativa e organizacional da unidade escolar, como horários, rotinas, etc. Em seguida, o supervisor escolar é quem se reúne com o professor iniciante, para desenvolver com ele uma conversa de cunho mais pedagógico, visando estabelecer um vínculo com esse profissional, com vistas a proporcionar um ambiente favorável para a sua atuação.

Essa dinâmica, fundamental para que o professor se sinta acolhido em seu contexto profissional, pode ser observada nos relatos dos diretores e das supervisoras:

É assim: primeiramente, quando ele chega à escola, o que a gente faz: a gente mostra toda a escola para ele, onde fica a biblioteca, a sala dos professores, secretaria, enfim, todo o espaço físico. Apresentamos ele para o grupo e depois, aí, assim, [...] a gente senta, a gente vê o horário, se for do $6^{\circ}$ ao $9^{\circ}$, se for do $1^{\circ}$ ao $5^{\circ}$, a gente fala quais são os dias que tem aula de educação física, as aulinhas-atividade. E depois ele é encaminhado para a supervisão; aí, ali, a supervisão vai dar todas aquelas orientações pedagógicas sobre o planejamento, sobre o dia a dia da sala de aula. (D5).

A minha prática é assim: eu costumo primeiro chamar o professor para conversar, passar todos os encaminhamentos que a escola tem, procuro deixar também ele bem à vontade, me colocar como uma pessoa que vai ajudar no processo, que se ele tiver qualquer dúvida que ele me procure, que eu vou estar sempre perto dele. Eu sempre deixo bem à vontade, para que a gente tenha essa relação de troca, para que o professor se sinta bem à vontade para me procurar quando necessário. (S5). (informações verbais).

Simon (2013) enfatiza que o acolhimento e o apoio são fatores determinantes no período de inserção profissional. Para a autora, os sentimentos positivos provenientes de um clima receptivo são estimuladores de práticas mais seguras. "Dessa forma, o acolhimento, mediante a valorização do novo profissional, será decisivo para a construção de uma parceria que beneficie tanto a instituição quanto aquele que passa a fazer parte de seu quadro funcional." (SIMON, 2013, p. 124). 
Paralelamente a essa recepção inicial, pôde-se observar outra ação de apoio oferecida ao professor iniciante. Trata-se do repasse de informações sobre o funcionamento da escola, por meio da apresentação de documentos, como o projeto político-pedagógico da unidade escolar, a proposta pedagógica e a matriz curricular. As falas a seguir, dos diretores e das supervisoras, elucidam tal ação:

\footnotetext{
[...] ele recebe toda a orientação com relação ao currículo a ser aplicado, toda a base curricular que é utilizada aqui na escola, conforme a Rede Municipal de Ensino. Ele recebe todas as orientações, ele recebe informações, inclusive recebe uma cópia do nosso plano político-pedagógico, e [...] dentro desse plano está o nosso contrato didático, são os nossos combinados. (D1).

[...] a gente tem um guia do professor com todas as informações, que é entregue todo ano para todos os professores. [...] a gente fez um resumo da proposta pedagógica, da questão da avaliação, conselho de classe, número de avaliações, o regimento, o que os alunos podem, o que não podem, o combinado com os professores, que foi construído com o próprio grupo de professores. (S2). (informações verbais).
}

Os documentos apresentados aos professores orientam o funcionamento da unidade escolar, portanto configuram-se como norteadores da prática pedagógica. 0 projeto político-pedagógico mencionado pelos diretores e supervisoras consiste em um documento redigido pela própria escola, com base na Lei de Diretrizes e Bases da Educação Nacional (LDB), Lei n. 9.394, de 20 de dezembro de 1996, e no Regimento Único das Unidades Escolares da Rede Pública Municipal de Ensino. 0 contrato didático e o guia do professor também são documentos organizados pela unidade escolar com base no projeto político-pedagógico e tratam das questões diárias da escola, ligadas tanto ao seu funcionamento quanto ao trabalho pedagógico, como: planejamento das aulas, tarefas, faltas, avaliação, provas, recuperação da aprendizagem, conselho de classe, calendário de avaliações, preenchimento de documentos burocráticos, organização e uso dos espaços físicos da escola, cumprimento das horasatividade do professor, entre outros.

0 repasse de tais informações parece vir ao encontro dos conhecimentos necessários ao professor apontados por Giovanni e Guarnieri (2014) e García (2009), cuja aquisição deve se dar mediante a prática docente no contexto escolar. Porém, apesar de esse repasse de informações sobre o funcionamento da escola ser considerado indispensável, acredita-se que tal ação não é suficiente para que o professor iniciante apreenda todos os aspectos burocráticos e pedagógicos inerentes à sua prática.

Simon (2013), em um estudo de caso sobre a inserção de professores iniciantes no campo profissional realizado em uma escola da educação básica, constatou que existe uma preocupação em instrumentalizar o professor iniciante por meio do conhecimento de documentos, planos e manuais que reportam o funcionamento e as normas institucionais. 
Porém, para a autora, "[...] o atendimento da supervisão está muito mais voltado para a manutenção da ordem nos movimentos didático-pedagógicos do que para o real auxílio aos novatos nos enfrentamentos cotidianos." (SIMON, 2013, p. 154, grifo nosso). Em vista disso, às vezes, as situações de rotina, que exigem uma orientação mais específica, ficam desguarnecidas. Ela assevera que,

\footnotetext{
Muito mais do que conhecer a estrutura e o funcionamento da instituição, é necessário que os novos professores tenham um acompanhamento constante em suas práticas diárias. Uma equipe, ou mesmo um professor mais experiente, que dispusesse de tempo para o atendimento, num espaço aberto para a escuta e a troca de experiências. (SIMON, 2013, p. 154).
}

Portanto, além desse momento inicial de recepção e repasse de informações, fazse necessário um acompanhamento efetivo no decorrer do exercício da profissão, a fim de minimizar as dúvidas e dificuldades que o professor iniciante possa encontrar em seu cotidiano profissional. Mais adiante, será discutida a maneira como se dá esse acompanhamento aos professores iniciantes na Rede de Ensino em questão.

Outra ação de apoio identificada no relato dos diretores diz respeito ao auxílio quanto ao domínio de turma. De acordo com Giordan (2014), em uma pesquisa realizada com professores iniciantes na mesma Rede Municipal de Ensino, um dos maiores desafios relatados pelos professores iniciantes refere-se à indisciplina dos alunos, que perpassa por questões como falta de educação e violência, perturbando e afetando prejudicialmente o ambiente de aprendizagem. A fala do Diretor 3 reflete a preocupação quanto à indisciplina dos alunos:

\footnotetext{
Eles vêm também pedir opinião da gente em relação, principalmente em relação à disciplina dos alunos. Eu acho que essa é uma das partes mais, que dá mais trabalho para eles, que é o maior desafio. Acho que até para a própria escola. É o maior desafio essa questão da disciplina hoje em dia, porque, em questão de conteúdos, eu sinto, assim, eles muito bem preparados, a grande maioria, principalmente desses novos, que eu sei que são novos na Rede. Então, esses meus professores novos, eu sinto, assim, que eles vêm com muita vontade, que eles vêm muito bem preparados, só que eu sinto que realmente essa parte da prática de lidar com os conflitos é algo que deixa eles bem instáveis, sabe? [...] E também vamos dando para eles várias dicas de como lidar com os alunos, que posturas eles devem ter, porque eu acho que é isso que vai fazer, assim, no decorrer do tempo, a diferença. (D3). (informação verbal).
}

De acordo com os dados coletados por Gabardo (2012, p. 80) na mesma Rede Municipal de Ensino, "[...] os problemas de indisciplina e a forma de lidar com os alunos constituem as principais fontes de mal-estar dos professores iniciantes" que atuam na 
Rede de Ensino investigada. Em sua pesquisa, a autora identificou as maiores dificuldades enfrentadas pelos iniciantes no exercício da docência. Entre as dificuldades mais recorrentes mencionadas pelos professores, destacam-se: "alunos que faltam com respeito para com o professor, sem interesse e agressivos/alunos sem valores", as quais ficaram bem à frente da opção "baixos salários e baixos investimentos em educação", por exemplo.

Calil (2014) afirma que a "(in)disciplina dos alunos" despontou como um dos principais desafios encontrados pelos professores iniciantes que atuam na Rede Municipal de Sobral, CE, lócus de sua pesquisa. Nas palavras da pesquisadora,

\footnotetext{
A escola tem se mostrado muito distante do interesse dos atuais alunos. A indisciplina pode ser um indício de que a atualização seja necessária na dinâmica da sala de aula, nos conteúdos, nas estratégias de ensino. Se um dos fatores que chama a atenção dos alunos é a competência do professor em ensinar e tal competência ajuda a legitimar a autoridade deste professor frente à sala de aula, ao se mostrarem frágeis didaticamente, os professores iniciantes certamente terão ainda mais dificuldade em conseguir manter a disciplina dos alunos. Cuidar da disciplina implica cuidar da relação professor-aluno. Tal relação não garante, mas interfere muito na aprendizagem dos alunos. Um relacionamento respeitoso e amistoso proporciona um bom clima para a aprendizagem e um fator importante para que o professor consiga exercer seu oficio. (CALIL, 2014, p. 149).
}

Portanto, é fundamental esse apoio dado ao professor iniciante quanto ao manejo de turma, pois, como apontado nas pesquisas, é comum os docentes enfrentarem desafios relacionados à indisciplina dos alunos no período de inserção profissional, o que reflete diretamente em seu bem-estar e, consequentemente, na qualidade da sua prática pedagógica. Contudo, acredita-se que apenas esse auxilio oferecido pela equipe gestora das escolas não seja suficiente para resolver o problema, considerando-se que se trata de uma solução imediata. Paralelamente a isso, impõe-se a necessidade de implementação de políticas educacionais que repensem a organização escolar, reduzindo o número de alunos por turma, por exemplo, e melhorem as condições objetivas de trabalho dos docentes, de modo a thes permitir a ministração de aulas que se tornem mais atrativas para os alunos. Certamente, as condições de trabalho enfrentadas pelos professores influenciam o cotidiano escolar e a qualidade da educação tanto quanto as estratégias de ensino e as dinâmicas praticadas pelos professores, iniciantes ou não. A formação continuada também tem importante papel no desenvolvimento profissional docente e deve ser ofertada com frequência, a fim de contribuir para o aprimoramento das competências didático-pedagógicas dos docentes.

Os dados coletados também revelaram uma outra ação de apoio positiva na organização da hora-atividade dos professores. Trata-se de organizar as aulas que os professores têm para a realização de seus planejamentos de forma a permitir que os professores iniciantes e experientes que lecionem para o mesmo ano escolar possam se 
encontrar pelo menos uma vez por semana para planejarem suas aulas em conjunto e, assim, trocarem experiências. 0 excerto a seguir descreve tal ação:

\begin{abstract}
[...] quando a gente recebe o professor, então, assim, a gente mostra a proposta pedagógica, a matriz curricular, [...] que está bem definida, então, o que se trabalha no $1^{\circ}$ trimestre, no $2^{\circ}$ trimestre, no $3^{\circ}$ trimestre, e dai a gente tenta organizar assim, uma mais experiente, tenho tentado, assim, organizar na educação fisica uma mais experiente com uma iniciante. Então, elas fazem, a gente faz uma jogada na educação física para elas ficarem juntas. Então, elas fazem um planejamento juntas; a mais experiente ajuda, e a mais nova contribui com a ideia nova e tem dado bem certo. (S1). (informação verbal).
\end{abstract}

Entretanto, apesar de apresentar-se como uma alternativa significativa para apoiar o docente iniciante, faz-se necessário dizer que essa ação é pontual e limitada, haja vista que nem sempre é possível organizar o horário das aulas de maneira a contemplar todos os professores com essa possibilidade de planejamento coletivo. Importante frisar também que essa forma de distribuição das aulas é mais comum nos anos iniciais do ensino fundamental, pois nos anos finais o número de professores que lecionam e a multiplicidade de componentes curriculares ministrados tornam mais complicada essa organização. 0 relato do Professor Experiente da própria Escola 1 aponta para essa dificuldade:

Nos [anos] finais ainda é mais complicado, porque tem professores que estão aqui, tem professores que estão em outras escolas, é mais difíicl. [...] porque, como a dinâmica ali é um pouco mais complicada, a questão de hora-aula, a troca de aula ali, então é difícil de fazer, unir todos eles no mesmo horário. De $1^{\circ}$ ao $5^{\circ}$ a gente consegue fazer isso, do $6^{\circ}$ ao $9^{\circ}$ complica um pouquinho mais. [...] às vezes eles se reúnem, têm projetos e fazem isso também. 0 que não consegue é, na sua prática, consegue trocar uma conversa ou outra ali, mas isso já complica mais de $6^{\circ}$ ao $9^{\circ}$, dificil, assim, porque tem professor aqui que, às vezes, tem cinco aulas na semana, dá aula em outras escolas, aí realmente não funciona muito, não; seria legal, mas é mais complicado. (PE1). (informação verbal).

Pode-se inferir, ainda, a partir do relato da supervisora, que não há um acompanhamento desse planejamento coletivo, o que caracteriza a organização da horaatividade como uma ação indireta da supervisão escolar. Ao prosseguir seu relato, a Supervisora 1 menciona que não consegue acompanhar os professores como deveria, por conta da demanda de trabalho frequentemente intensificada por excessivas substituições de professores faltantes. Desse modo, percebe-se que as condições objetivas de trabalho vivenciadas cotidianamente nas escolas não favorecem a realização de um trabalho coletivo por parte dos professores, nem por parte destes e dos supervisores, como sugerem Nono (2011) e Libâneo (2008), prevalecendo, então, um trabalho isolado e fragmentado. 
No entanto, a experiência do Município de Sobral, investigada por Calil (2014), configura-se como um exemplo de que é possível outra forma de organização do momento de planejamento. A pesquisadora relata que, quinzenalmente, os coordenadores pedagógicos se reúnem com os professores na escola durante quatro horas, no próprio período de aula, a fim de, juntos, realizarem o planejamento. Enquanto isso, as salas de aula desses docentes são atendidas por professores substitutos, visto que cada escola possui um "banco de professores substitutos" para os momentos em que os demais professores estão em planejamento ou em formação continuada. 0 planejamento é pautado em ações vistas durante a formação em serviço, e o coordenador pedagógico tem a função de acompanhar o professor ao longo desse processo. Compreende-se que essa organização do trabalho faz parte de uma política de formação pensada para toda a rede do município, e, havendo interesse político, é possível que as Secretarias de Educação ofereçam melhores condições de trabalho para seus docentes, o que certamente interfere na qualidade da educação.

No que tange à formação em serviço, ação de apoio também constatada na pesquisa, fica evidente que esse é um trabalho desenvolvido pelas supervisoras escolares, conforme aponta a Supervisora 4:

\footnotetext{
[...] eu faço, assim, formação com os professores. Então, por exemplo, tenho $1^{\circ}$ e $2^{\circ}$ ano, eu reúno os professores do $1^{\circ}$ e $2^{\circ}$ ano, sejam eles iniciantes ou não, e trabalho alguma coisa com eles que seja, vamos dizer, necessária naquele momento: eu observei que está acontecendo alguma coisa nas aulas e aquilo precisa ser modificado. Então, de repente, a gente conversa sobre isso, entende? Eu vou atacando os pontos, [...] é mais direcionado mesmo para resolver alguns problemas. (S4). (informação verbal).
}

0 relato permite inferir, que as formações com os professores são realizadas a partir das necessidades observadas no cotidiano escolar, buscando solucionar problemas pontuais. Notadamente, essa prática é essencial no contexto escolar, pois visa aprimorar os processos de ensino-aprendizagem. No entanto, a partir dessa fala, pode-se inferir que esse processo de formação em serviço não é sistemático, como defende Libâneo (2008), mas esporádico, conforme surgem as demandas. A formação continuada em serviço dentro do próprio espaço escolar apresenta-se como uma alternativa relevante para o processo de inserção profissional e também para o desenvolvimento profissional docente. Como salientado por Imbernón (2011), quanto mais se aproximar do contexto organizacional do trabalho, mais efetiva tal formação será.

Tendo em vista que a formação continuada de professores se configura como uma das atribuições do supervisor escolar, acredita-se que a escola pode se transformar em uma comunidade de aprendizagem tendo o próprio supervisor como condutor/mediador desse processo, contribuindo, assim, para o desenvolvimento profissional não apenas 
dos professores iniciantes mas também dos mais experientes. Compreende-se, portanto, que, para a efetivação de um processo de formação continuada nesses moldes, faz-se necessário o estabelecimento de tempos e espaços para que os membros da comunidade escolar possam interagir entre si, seja por meio de reuniões pedagógicas frequentes que contemplem as especificidades de cada escola, seja pela implementação de grupos de estudo ou outras formas de encontros sistemáticos que possibilitem a troca entre os pares. Assim, o supervisor escolar seria o mediador desse processo coletivo, e não o único responsável pelo apoio e acompanhamento aos docentes.

Quanto ao acompanhamento do professor iniciante no contexto escolar, os dados evidenciam que essa prática é desenvolvida preponderantemente pelos supervisores escolares, ao passo que os diretores estão mais presentes nos momentos iniciais de recepção ao docente novato e também nos períodos de avaliação do estágio probatório. As falas indicam, ainda, que os diretores buscam proximidade com os professores iniciantes em momentos como o recreio, as reuniões pedagógicas e os conselhos de classe, com o objetivo de identificar formas de apoiá-los. A partir dos relatos, é possivel inferir que os diretores não conseguem acompanhar o professor iniciante de maneira sistemática, observando seu planejamento e sua atuação pedagógica. Nos excertos a seguir, os diretores falam sobre o acompanhamento que realizam junto ao professor iniciante:

\footnotetext{
Quem acompanha mais especificamente esse professor é a supervisão, assim, no que diz respeito ao pedagógico especialmente. $E$ a gente, um pouco mais na questão do administrativo, a questão do estatuto do servidor, o vinculo com a prefeitura, a questão do ponto, de faltas e assiduidade. $A$ gente entra mais nessa parte administrativa. (D4).

A direção e a supervisão, assim, geralmente a supervisão está repassando para a direção: "Ah, aquele professor está assim, ele precisa de uma orientação." Então, a direção, geralmente a gente está junto com a supervisão na hora, [para] dar uma orientação. Muitas vezes ele participa de formação continuada em serviço mesmo, a supervisão chama ele; quando há necessidade, eu também estou junto. (D5) (informaç̃̃es verbais).
}

Como já mencionado, Souza (2010) revela que o trabalho do diretor se dá em duas perspectivas, a político-administrativa e a político-pedagógica. Contudo, percebe-se uma predominância da atuação do diretor escolar com relação aos aspectos administrativos do acompanhamento do professor iniciante. Os diretores parecem participar do acompanhamento pedagógico apenas quando solicitados pelo supervisor. Souza (2010) adverte que, no desempenho de suas funções, o diretor pode e deve contar com o trabalho do coordenador pedagógico, "[...] constituindo uma equipe de gestão escolar descentralizada e participativa, o que possibilita maior alcance dos objetivos institucionais, da efetiva gestão democrática e da qualidade do ensino." Evidentemente, considera-se necessária a distinção entre as 
funções de diretor e supervisor; contudo, tal forma de organização do trabalho não pode restringir a atuação do diretor apenas aos aspectos administrativos do acompanhamento aos professores iniciantes, visto que sua função tem também um caráter político-pedagógico.

Em pesquisa desenvolvida com professores iniciantes e atuantes nos anos iniciais do Ensino Fundamental, Leone (2011, p. 246) também constatou “[...] a pouca participação da direção das escolas no sentido de proporcionar apoio e/ou orientação aos professores iniciantes." A autora destacou que o apoio oferecido pelos coordenadores pedagógicos aos docentes iniciantes se sobressai em relação ao apoio oferecido pelos diretores.

As pesquisas realizadas por Gabardo (2012) e Giordan (2014) com professores iniciantes na Rede Municipal de Ensino em questão apontaram para a centralidade do supervisor escolar na recepção e no acompanhamento dos docentes iniciantes. Gabardo (2012, p. 68) afirma que "[...] a 'acolhedora' recepção pela rede está vinculada, principalmente, à figura do supervisor de ensino, que [...] é o profissional responsável por receber e acompanhar os professores ingressantes durante e após o estágio probatório." Giordan (2014, p. 104) destaca que "[...] os professores, quando perguntados sobre quem os acompanha e como é realizado esse acompanhamento, destacam o papel do supervisor escolar como a pessoa que está mais próxima no dia a dia de seu trabalho."

A prevalência da prática de acompanhamento pedagógico por parte da supervisão evidenciou-se nas falas das supervisoras escolares, que, ao descreverem o trabalho que desenvolvem junto aos professores iniciantes, utilizaram expressões como "acompanhar", "orientar", "apoiar" e "dar suporte". Os excertos a seguir apontam para a compreensão do papel do supervisor escolar no processo de acompanhamento do docente iniciante:

É, eu acho que supervisão não é supervisionar, é acompanhar mesmo,
ajudar ele a entrar [...] cada empresa tem sua regra, e não é diferente na
Educação no Município. E eu acho que ele tinha que tentar se adequar à
forma que a gente trabalha e ver também quais são as necessidades deles.
Acho que é isso que o supervisor faz, ou deveria fazer. (S3).
É orientar, é acompanhar o pedagógico. A supervisão dentro da escola,
tem o papel de organizar toda a área pedagógica; então, todos os
encaminhamentos da área pedagógica é a supervisão que faz. Então,
são projetos, é reforço, é Sala de lnformática, Biblioteca, Sala de Recursos
Multifuncionais, tudo organizado pela supervisão. (S4). (informações verbais).

Alguns aspectos podem ser destacados desses depoimentos, como, por exemplo, a expressão extraída da fala da Supervisora 3 na seguinte afirmação: “É, eu acho que supervisão não é supervisionar, é acompanhar mesmo [...]" Nota-se, na fala da supervisora, a referência ao sentido historicamente construído em torno da palavra "supervisor", remetendo 
a certo controle exercido sobre algo ou alguém e a sinalização de que essa visão não é mais adequada ao contexto educacional da atualidade.

Já o relato da Supervisora 4 ilustra a dimensão do trabalho desempenhado pelas supervisoras escolares, compreendendo atividades relacionadas ao funcionamento pedagógico da escola e ao apoio oferecido aos professores, como revelado por Placco, Souza e Almeida (2012).

Além de demonstrar que possuem clareza quanto à função de apoiar e acompanhar o professor iniciante, as supervisoras esclareceram como realizam o acompanhamento desses profissionais: "é no dia a dia, você vai visitando sala, você vai olhando aula, planejamento, tirando dúvida, chamando para reunião, dando orientação, é assim que funciona." (S4) (informação verbal).

\footnotetext{
[...] eu deixo muito eles virem com as dúvidas para, num primeiro momento, eles [pausa], porque, senão, o que acontece: se a gente bloquear, se a gente for já dizendo tudo que têm que fazer, eles vão se fechando. Alguns estão em início de carreira; quando é início de carreira, as dúvidas são mais ainda. Então, no primeiro momento, eu vou tirando as dúvidas e orientando conforme vai acontecendo as atividades, trocando ideias. Porque a minha maior função é trocar ideias, é propiciar que ele aprenda na prática, quando não tem o conhecimento. [...] e, no decorrer dos meses do trimestre, a gente tem o acompanhamento; eu sempre procuro na aulaatividade para conversar, sempre estou passando por ele: "Ah, está com alguma dificuldade?" Eu sempre digo para eles que eu fico passando nos corredores. Então, é mais difíil me encontrar na minha sala, é mais fácil encontrar na sala de aula. "Quando você me ver e se tiver alguma dúvida, se precisar de alguma coisa, pode me chamar para dar o apoio", porque, nesse primeiro momento, eles precisam de um apoio até para poder entrar nesse mundo da educação. (S2). (informação verbal).
}

As supervisoras expressam preocupação em criar um ambiente de liberdade e segurança para o docente, procurando não o sufocar, mas, sim, deixá-lo à vontade para realizar seu trabalho e solicitar apoio e orientação quando julgar necessário.

Os dados apresentados na pesquisa de Giordan (2014, p. 104) evidenciaram que os supervisores são vistos como "companheiros" dos iniciantes, pois "[...] realizam um acompanhamento bem próximo do trabalho do professor, principalmente assistindo a aulas, orientando e observando o planejamento e conteúdos."

É perceptível, porém, que não existe um período específico para essas orientações, mas que elas se dão no dia a dia da prática do professor, conforme surgem as necessidades. Elas podem ocorrer tanto em sala de aula quanto no corredor ou na sala da supervisão, ou seja, não há uma sistematização desse processo. Por um lado, considera-se fundamental essa forma de acompanhamento, pois permite a aproximação entre supervisor e professor. 
Por outro lado, corre-se o risco de que essa seja a única forma de apoio aos docentes, deixando-se de lado a criação de tempos e espaços específicos para um acompanhamento sistemático do processo de inserção. Por conseguinte, se o docente não solicitar apoio com certa frequência, poderá correr o risco de não ser acompanhado como deveria.

Os relatos das próprias supervisoras apontaram para um problema que também pode limitar a efetivação desse acompanhamento. Trata-se da rotina de trabalho intensa que lhes é imposta no cotidiano escolar em razão do tempo que passam realizando atividades emergenciais, como a substituição de professores faltantes, por exemplo. 0 relato a seguir expressa tal situação:

\begin{abstract}
Nós vivemos uma realidade bem conturbada, assim: por dia faltam quatro, cinco professores Então a gente faz o máximo para conseguir acolher aquele professor. Eu tento fazer muita coisa por escrito para eles, porque eu sei que no dia a dia eu vou estar em sala de aula e é complicado. Então, pelo menos uma vez por semana, de duas em duas semanas, eu vou, fico um pouquinho com ele, pergunto quais são, se ele tem algum problema, alguma dificuldade para tentar sanar naquele horário, porque a gente tem um dia a dia bem corrido. (S3). (informação verbal).
\end{abstract}

0 relato da Supervisora 3 evidencia a falta de tempo para acompanhar sistematicamente o professor iniciante, exigindo que sejam pensadas outras maneiras de acompanhá-lo e orientá-lo. A alternativa encontrada pela Supervisora 3 para contornar essa situação é a orientação por escrito, que, além de caracterizar uma forma de registro do acompanhamento efetuado, também pode permitir cobranças futuras pautadas em tais registros, apontando para uma possível forma de controle desse professor. Todavia, acredita-se que um acompanhamento pessoal que proporcione a troca de experiências e uma orientação voltada diretamente ao problema enfrentado sejam igualmente necessários ao processo de inserção dos professores.

A Supervisora 1 também fez menção a esse problema e apontou as alternativas que utiliza na tentativa de amenizá-lo:

Porque, na verdade, a gente não está conseguindo; eu acompanho assim: eu tenho, por exemplo, agora eu estou cheia de atividades lá que eu tenho que corrigir. Então essa semana, semana passada, eu estava na substituição de dois $2^{\circ}$ anos; então, eu fiz uma sequência didática [...] então, cada vez que eu faço isso, eu já faço um balanço para ver como é que está o nível dos $2^{\circ}$. Agora eu estou quase acabando de corrigir todas, daí eu faço um relatório e dou a devolutiva. E daí as professoras mais novas eu costumo acompanhar com mais frequência na sala, as professoras velhas, gente, eu não acompanho mesmo, não tem como. Então, a gente faz na metade do trimestre um pré-conselho; então, por conta dessa avaliação que eu faço agora, que eu fiz semana passada, eu faço um relatório. Então, eu vejo 
como é que está a turma, dai eu faço as orientações. [...] Aí os casos, assim, a turma foi, dos quatro $2^{\circ \mathrm{s}}$ anos, essa turma foi muito fraca. Por que ela foi muito fraca? A gente faz uma análise: "foi daquela professora específica", muitas vezes acontece assim das professoras novas [...] (S1). linformação verbal).

Nesse caso, as orientações por escrito são elaboradas a partir do trabalho desenvolvido com as turmas, e não da observação direta do trabalho do professor. Essa prática parece sinalizar para uma possivel cobrança por resultados que recai sobre - professor, o que pode ser reflexo do atual sistema de avaliação externa, que vem ganhando cada vez mais força, tanto no âmbito municipal quanto federal. Por conseguinte, os esforços que deveriam ser direcionados para o acompanhamento da prática pedagógica do professor a fim de contribuir para seu desenvolvimento profissional parecem se deslocar para o monitoramento dos resultados dos alunos, incidindo em cobranças e, por vezes, em culpabilização do professor por tais resultados, desconsiderando as condições de trabalho a que esse profissional está submetido. Desse modo, infere-se que essa prática da supervisão escolar pode, ainda, caracterizar-se como uma forma de controle do trabalho desempenhado pelo professor.

A Supervisora 1 enfatiza também que não consegue acompanhar regularmente todos os professores e por isso prioriza o acompanhamento dos mais novos na escola. Contudo, convém pontuar que nessa Unidade Escolar há duas supervisoras, uma para os anos iniciais e uma para os anos finais, fato que poderia minimizar a demanda de trabalho dessas profissionais se comparado à realidade de outras escolas que possuem apenas uma supervisora para atender todo o Ensino Fundamental. Ainda assim, essa profissional tem 24 professores sob sua supervisão. Ao longo de seu relato, a Supervisora 1 também fez menção a projetos provenientes da Secretaria Municipal de Educação, cujo desenvolvimento fica sob sua responsabilidade, inclusive as devolutivas à Secretaria, elaboradas por meio de relatórios e apresentações do trabalho realizado com os alunos. Esse conjunto de fatores, associado ao grande número de substituições a serem realizadas no cotidiano das escolas, parece indicar uma sobrecarga de trabalho das supervisoras escolares e, consequentemente, pode inviabilizar a realização de um acompanhamento mais sistemático do professor iniciante.

A substituição de professores foi recorrente nas falas das supervisoras, sendo mencionada também por diretores e professores experientes, o que ratifica a dimensão do problema. A falta de professores é apontada por Almeida (2010) como um dos grandes desafios enfrentados no cotidiano das escolas públicas. Evidentemente, essa situação tem prejudicado a efetivação de um acompanhamento mais adequado não só aos professores iniciantes, mas a todos os profissionais que estão sob a supervisão desse profissional.

Almeida (2010), em artigo intitulado Um dia na vida de um coordenador pedagógico de escola pública, apresenta uma pesquisa realizada com 10 coordenadores pedagógicos, 
que foram provocados a descrever um dia típico de trabalho na sua função. Os resultados da pesquisa apontam para um movimento frenético vivenciado no cotidiano da escola, proveniente de uma série de atividades a serem realizadas diariamente pelos coordenadores pedagógicos, como:

[...] organização e execução de horários coletivos de trabalho pedagógico; organização do início dos períodos; relações formais e informais com direção, professores, alunos, pais, órgãos superiores; leitura de redes e comunicados referentes às atividades que envolvem professores e alunos $e$ elaboração de relatórios; atendimento às emergências. (ALMEIDA, 2010, p. 23).

Placco (2010, p. 47) salienta que o cotidiano do coordenador pedagógico "[...] é marcado por experiências e eventos que o levam, com frequência, a uma atuação desordenada, ansiosa, imediatista e reacional, às vezes até frenética", frustrando suas intencionalidades e seus propósitos e levando-o, dadas as circunstâncias, a responder às situações do momento "apagando incêndios". Em meio a tantas atribuições conferidas ao supervisor escolar lou coordenador pedagógico) e em razão do cotidiano intenso característico das escolas, parece não restar tempo para que esse profissional desempenhe seu trabalho pedagógico junto ao professor, como descreve a Supervisora 5: "Mas o básico mesmo do supervisor é com o professor." (informação verbal).

Tratando-se das condições objetivas de trabalho enfrentadas pelos supervisores escolares, convém mencionar a política adotada no Município de Sobral, CE. De acordo com Calil (2014), o número de coordenadores em cada unidade escolar é calculado pelo número de matrículas, na proporção de um coordenador para cada 250 alunos, havendo escolas com até seis coordenadores. Como já mencionado anteriormente, no Município de Sobral há também um banco de professores substitutos para os momentos em que os professores estão em formação continuada em serviço, fora da escola, ou em planejamento, com o acompanhamento do coordenador pedagógico. Portanto, acredita-se que o número reduzido de professores e turmas a serem acompanhadas por cada coordenador pedagógico e a isenção das substituições de professores faltantes são fatores que podem contribuir significativamente para a melhoria das condições objetivas de trabalho desses profissionais, refletindo também na qualidade do trabalho realizado pelos coordenadores junto aos professores e seus alunos.

Em linhas gerais, pode-se afirmar que existe, sim, nas escolas da Rede Municipal de Ensino desse Município, um acompanhamento dos professores iniciantes, que, de acordo com as pesquisas de Gabardo (2012) e Giordan (2014), é valorizado por esses docentes. Contudo, constatou-se que a efetivação desse acompanhamento é determinada pelas condições de trabalho vivenciadas pelos supervisores escolares, que, frequentemente 
envolvidos no atendimento às atividades emergenciais do contexto escolar, não conseguem realizar um acompanhamento mais sistemático, observando aulas e assessorando na elaboração do planejamento, como previsto pelo Regimento Único das Unidades Escolares da Rede Pública Municipal de Ensino. Tal situação tem gerado, inclusive, um sentimento de frustração nesses profissionais.

\section{ALGUMAS PROPOSIÇÕES FINAIS}

Tomando por base os achados decorrentes desta investigação, propõemse algumas alternativas como forma de contribuir para a concepção de ações voltadas para o apoio e o acompanhamento de professores iniciantes. Algumas dessas proposições configuram-se como medidas emergenciais que poderiam ser aplicadas pelas próprias escolas, buscando minimizar os maiores problemas por elas enfrentados atualmente. Já outras poderiam ser implementadas por meio das Redes de Ensino, a fim de melhorar as condições de trabalho do docente iniciante e daqueles que o acompanham no dia a dia.

Assim, propõe-se a ampliação e a qualificação do tempo e do espaço para planejamento coletivo, pois, a exemplo da experiência vivenciada em uma das escolas que constituíram o lócus desta investigação, a possibilidade de planejamento coletivo tem se mostrado como uma prática significativa para os professores, iniciantes ou experientes. Portanto, organizar o horário escolar de modo a permitir esse encontro para o maior número de professores pode contribuir para a troca de experiências e, consequentemente, para o desenvolvimento profissional dos docentes.

A ampliação da formação em serviço, com a realização de reuniões pedagógicas regularmente, em espaços destinados à socialização e à troca de experiências também pode ser uma alternativa para o desenvolvimento de um trabalho mais coletivo e colaborativo. Importante frisar que, paralelamente à troca de experiências, é fundamental que haja discussão sobre aspectos teóricos da profissão docente que possam embasar a prática pedagógica e apontar para a solução de problemas enfrentados no cotidiano de cada unidade escolar.

Propõe-se, ainda, a ampliação do número de supervisores por unidade escolar, a fim de facilitar o trabalho desses profissionais junto aos professores e permitir um acompanhamento mais sistemático da prática pedagógica dos docentes. Tal ação também poderia contribuir para o planejamento de formações em serviço que atendam mais especificamente às necessidades de cada segmento do Ensino Fundamental.

Acredita-se também que a existência de professores volantes e/ou substitutos, que possam atender as turmas nos casos de ausência de professores, contribuiria com a 
melhoria das condições objetivas de trabalho da equipe gestora, principalmente da supervisão escolar, permitindo-lhe mais tempo para desempenhar sua função junto aos professores, tanto iniciantes quanto experientes.

\section{REFERÊNCIAS}

ALMEIDA, L. R. de. Um dia na vida de um coordenador pedagógico de escola pública. In: PLACCO, V. M. N. de S.; ALMEIDA, L. R. de (org.). 0 coordenador pedagógico e o cotidiano da escola. São Paulo: Edições Loyola, 2010. p. 21-46.

CALIL, A. M. G. C. A formação continuada no município de Sobral (CE). 2014. 202 f. Tese (Doutorado em Educação: Psicologia de Educação) - Pontificia Universidade Católica de São Paulo, São Paulo, 2014.

FRANCO, M. L. P. B. Análise de conteúdo. 4. ed. Brasília, DF: Liber Livro, 2012.

GABARDO, C. V. L. 0 início da docência no ensino fundamental da rede municipal de ensino. 2012. 127 f. Dissertação (Mestrado em Educação) - Universidade da Região de Joinville, Joinville, 2012.

GARCÍA, C. M. A identidade docente: constantes e desafios. Revista Brasileira de Pesquisa sobre Formação Docente, Belo Horizonte, v. 1, n. 1, p. 109-131, ago./dez. 2009. e-ISSN 2176-4360.

GARCÍA, C. M. Formação de professores: para uma mudança educativa. Porto: Porto Editora, 1999.

GIORDAN, M. Z. Professores iniciantes dos anos finais do ensino fundamental: desafios e dilemas. 2014. 152 f. Dissertação (Mestrado em Educação) - Universidade da Região de Joinville, Joinville, 2014.

GIOVANNI, L. M.; GUARNIERI, M. R. Pesquisas sobre professores iniciantes e as tendências atuais de reforma da formação de professores: distância, ambiguidades e tensões. In: GIOVANNI, L. M.; MARIN, A. J. (org.). Professores iniciantes: diferentes necessidades em diferentes contextos. Araraquara, SP: Junqueira\&Marin, 2014. p. 33-44.

HUBERMAN, M. 0 ciclo de vida profissional dos professores. In: NÓVOA, A. (org.). Vidas de Professores. 2. ed. Porto, Portugal: Porto Editora, 2007. p. 31-62.

IMBERNÓN, F. Formação docente e profissional: formar-se para a mudança e a incerteza. 9. ed. São Paulo: Cortez, 2011.

LEONE, N. M. Necessidades formativas dos professores dos anos iniciais na sua inserção no exercício da docência. 2011. 315 f. Dissertação (Mestrado em Educação) - Universidade Estadual Paulista, Presidente Prudente, 2011.

LIBÂNEO, J. C. Organização e gestão da escola: teoria e prática. 5. ed. Goiânia: MF Livros, 2008. 
NONO, M. A. Professores iniciantes: o papel da escola em sua formação. Porto Alegre: Editora Mediação, 2011.

PLACCO, V. M. N. de S. 0 coordenador pedagógico no confronto com o cotidiano da escola. In: PLACCO, V. M. N. de S.; ALMEIDA, L. R. de (org.). 0 coordenador pedagógico e o cotidiano da escola. São Paulo: Edições Loyola, 2010. p. 47-60.

PLACCO, V. M. N. de S.; SOUZA, V. L. T. de; ALMEIDA, L. R. de. 0 coordenador pedagógico: aportes à proposição de políticas públicas. Cadernos de Pesquisa, São Paulo, v. 42, n. 147, p. 754-771, set./dez. 2012. ISSN 0100-1574. DOl http://dx.doi.org/10.1590/S0100-15742012000300006.

SIMON, M. S. Inserção de professores iniciantes no campo profissional: um estudo de caso na escola básica. 2013. 210 f. Tese (Doutorado em Educação) - Pontificia Universidade Católica do Rio Grande do Sul, Porto Alegre, 2013.

SOUZA, A. L. L. de. Direção escolar. In: OLIVEIRA, D. A.; DUARTE, A. M. C.; VIEIRA, L. M. F. Dicionário: trabalho, profissão e condição docente. Belo Horizonte: UFMG, 2010. 1 CD-ROM.

Endereços para correspondência: Rua São José, 490, Bairro Anita Garibaldi, 89202-010, Joinville, Santa Catarina, Brasil; dirlenegla@gmail.com 
